This is the author's version of a work that was submitted to / accepted for publication. Citation for final published version:

Madge, N., Hemming, P.J., Goodman, A, Goodman, S. Kingston, S., Stenson, K. \& Webster, C. 2012. Conducting large-scale surveys in secondary schools: the case of the Youth On Religion (YOR) Project. Children \& Society 26(6), pp. 417-429. (10.1111/j.10990860.2011.00364.x)

\title{
Conducting Large-Scale Surveys in Secondary Schools: The Case of the Youth On Religion (YOR) Project
}

Nicola Madge*, Centre for Child and Youth Research, Brunel University

Peter J. Hemming, Centre for Child and Youth Research, Brunel University

Anthony Goodman, Department of Criminology and Sociology, Middlesex University

Sue Goodman, Department of Criminology and Sociology, Middlesex University

Sarah Kingston, Faculty of Health and Social Sciences, Leeds Metropolitan University

Kevin Stenson, School of Social Policy, Sociology and Social Research, University if Kent

Colin Webster, Department of Criminology, Leeds Metropolitan University

*Correspondence to: Professor Nicola Madge, Centre for Child and Youth Research, Brunel University, Uxbridge, Middlesex UB8 3PH, UK, Tel.: +44 (0)1895 268732; Fax: +44 (0)1895 269853. E-mail: nicola.madge@brunel.ac.uk

\begin{abstract}
There are few published articles on conducting large-scale surveys in secondary schools, and this paper seeks to fill this gap. Drawing on the experiences of the Youth On Religion project, it discusses the politics of gaining access to these schools and the considerations leading to the adoption and administration of an online survey. It is concluded that successful research in schools has to be planned carefully in collaboration with key members of staff, and justified as an educational activity. Providing speedy feedback was helpful to ensure schools benefited from the research and to keep them engaged with the project.
\end{abstract}

Keywords: young people, methodology, schools, religion, online survey 


\section{Introduction}

Conducting research in schools presents particular challenges in the current British climate as Head Teachers face both increasing levels of requests to undertake surveys and a greater administrative burden (Sturgis and others, 2006). Despite many studies reporting findings from research carried out in schools, few provide critical commentary on the research process per se. Some authors discuss specific issues such as gatekeepers, gaining informed consent and ethical dilemmas (David and others, 2001; Dinella and Ladd, 2009; Gill, 2003), or the merits of different survey procedures (see below), but otherwise there is a notable shortage of published information on this important aspect of the research process (Testa and Coleman, 2006). This article describes the experiences of the Youth On Religion (YOR) project in facing up to the challenges and carrying out a large-scale school-based survey. It examines issues of developing the survey methodology, identifying secondary schools (and, in two cases, colleges) and getting them on board, administering the survey, ensuring that only members of the research sample take part, and gaining some feedback from participants.

The aim of the YOR project is to fill a gap in the research literature by exploring the meaning of religion in young people's lives in three British study locations with distinct characteristics of religious history, diversity and social deprivation. In brief, the specific research questions are:

- What are young people's perceptions of their own religious identity, and is religion important to them?

- How is the development of their religious identity linked with individual (e.g. gender, class), social (e.g. family, friendship, religious and ethnic group) and spatial (e.g. where they live, go to school and visit) variations?

- What do young people see as the positive and less positive aspects of religion?

- How do young people think social cohesion can be encouraged and promoted within diverse religious groups? 
Existing knowledge on these questions is either scarce or out-of-date, largely due to recent demographic changes in Britain, the increasing impact of globalisation through the mass media and the rarity of research on this theme. To take account of religious diversity within the overall population, as well as different geographical patterns, the YOR project involves both a large-scale survey and qualitative investigation. This article describes the process of carrying out a school-based survey from its inception to the point of data collection.

\section{The survey methodology}

Although it was clear from the outset of the YOR project that we wished to carry out a school survey, we were less certain about its format. The paper and pen questionnaire has been the traditional tool of large-scale surveys, but an online version provided an attractive alternative. The cost in time and resources of administering a paper questionnaire would be enormous. But would schools be able to organise an online survey? Practical and research considerations, and costs, ultimately influenced our decisions on survey methodology.

\section{Practical considerations}

Both computer-based and paper surveys have some key practical benefits (Table 1). Online questionnaires do not need to be printed and posted, they can include multimedia objects, questions can be much more easily changed, participants need only a computer and internet access, and anonymity is more easily assured. Moreover, there are fewer ambiguous responses (e.g. respondents can tick only permitted options and there is no handwriting to be deciphered), no need for data entry bedevilled by human error, and data are automatically stored. Young people also seem to prefer computer-based to paper questionnaires because they are more engaging (e.g. Martin, 1995). Another advantage of computer-based surveys is that progress and response patterns can be monitored instantly (LaBrie and others, 2006). Paper questionnaires, on the other hand, can be completed anywhere and anytime without computer access or literacy. Respondents can see the full questionnaire before they start, and review progress as they proceed. They can also easily answer questions in their preferred order. 


\begin{tabular}{|l|l|}
\hline Computer-based & Paper \\
\hline - No printing or posting & - Can be done anywhere \\
- Fewer ambiguous responses & - Easier for respondents to see the number \\
- No data entry & of questions and what they are \\
- Easier to change questions & - Easier to answer questions in preferred order \\
- Extra facilities, e.g. branching & - No need to be computer literate \\
- Fully anonymous & - Easier to assess response rate \\
- Can make 'lively' and 'colourful' & \\
- More fun & \\
- Data easily stored & \\
- Progress instantly visible & \\
\hline
\end{tabular}

Table 1: Some advantages of computer-based and paper questionnaires

An important practical consideration in our study, if we were to use an online questionnaire, was whether schools would have sufficient computers for pupils to undertake the survey during the six-week period in question. Understanding the organisation of schools, and particularly computer provision and allocation, was therefore critical in determining likely response rates (Testa and Coleman, 2006). Despite the launch of the first national ICT strategy in 1997, the investment of billions of pounds and widespread in-service training for teachers, the translation of government policy on ICT in UK schools into reality has been a slow and complicated process in which legislative requirements have not been met (Younie, 2006). Nonetheless, a sufficient number of schools appeared confident that they could arrange for target pupils to undertake the YOR online survey during lesson times. This factor contributed to our decision to opt for an online survey.

\section{Research considerations}

Research considerations are also important. Key questions for the YOR project were whether response and non-response rates would differ with computer-based and paper questionnaires, and whether the format would affect answers young people gave. 
Much evidence on response rates from online and paper questionnaires (which often compares internet and postal questionnaires) is not directly relevant to the YOR project. Our survey would, whichever approach we adopted, be undertaken in a classroom setting. The issue of differential non-response rates (i.e. differences in patterns of questions left unanswered) is, however, more complex. We would expect a drop-off in response levels as the questionnaire proceeded, but would the format of the questionnaire affect patterns of responses in other ways? Evidence from the literature is mixed (Sax and others, 2003). In their own American exploratory study, these authors studied 4416 college students and, within an overall response rate of $21.5 \%$, found no discernible differential effects of using online or paper questionnaires. Questionnaire response seemed most likely where respondents perceived the topic of inquiry as relevant to their own lived experiences.

A further question is whether young people might answer questions differently for online or paper questionnaires. Some authors have discussed an online disinhibition effect whereby the online environment encourages respondents to disclose more than they would in a faceto-face interaction (Joinson, 2001; Postmes and others, 2001; Suler, 2004). Suler (2004) further distinguishes between benign disinhibition (revealing more personal information, secret emotions, etc.) and toxic disinhibition (becoming more rude, harsh and extreme).

Limited and somewhat contradictory evidence exists on response differences in the two types of setting. LaBrie and others (2006) compared responses to computer-based and paper questionnaires and found minimal differences. The research methodology of this study could, however, be criticised for involving the same respondents in completing an anonymous 10-min paper-based survey and the identical survey using wireless handheld keypad devices in a single session. Somewhat different findings are reported by BoothKewley and others (2007). These authors found that an online rather than a paper format led to higher reported rates of alcohol and risky sex, and offered support for Feigelson and Dwight's (2000) conclusion that 'more candid responses' are gained through using a computer. Other studies, nonetheless, have suggested few differences in responses to specific psychological assessments using online or paper means (Ritter and others, 2004; Vallejo and others, 2007). 


\section{Costs}

The question of cost was also important in determining our decision to adopt an online survey for the YOR project. Rough calculations, based on estimates received from an external data management company, online survey companies and the University, established the comparative resource implications of the different options. In each case, these were based on the expectation of a survey of around 10000 young people in a large number of schools in three different research locations. Four different survey options were considered: an online survey; a paper survey administered through the University and involving printed questionnaires and manual data input; a paper survey carried out fully by a data management company; and a paper survey administered through the University and using University scanning facilities. Figure 1 shows our estimate of the costs of each option and suggests that the online survey option was much the cheapest choice.

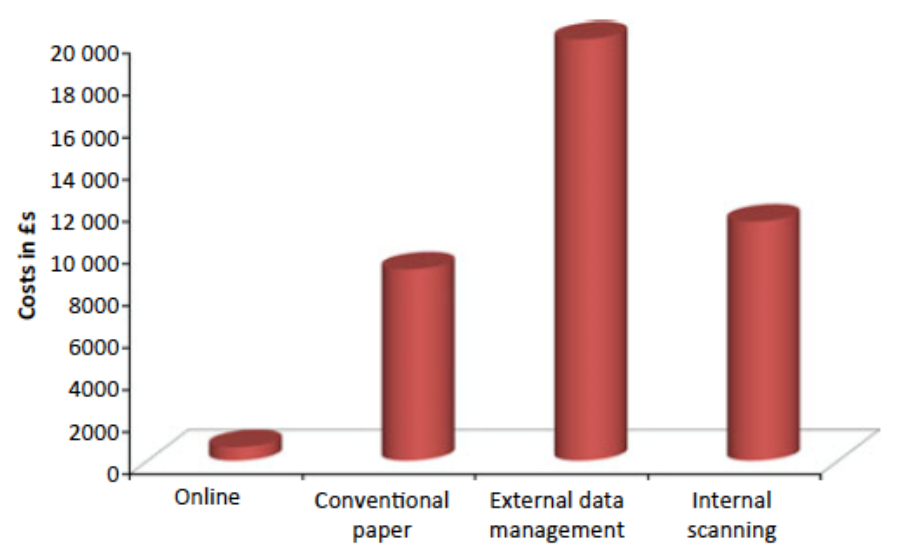

Figure 1: Estimated costs (£s) for four different survey options.

\section{A mixed strategy?}

Before making our final decision, we also considered the possibility of offering schools the choice of an online or paper questionnaire. This option was, however, quickly abandoned. Pupils under the two conditions would not be receiving the identical questionnaire (e.g. no branching, etc.) and we were concerned we might get different patterns of responses that it 
could be difficult to identify and account for (Query and Wright, 2003). Dillman (2000) points to the problems inherent in using a mixed approach of this kind, particularly if those displaying non-response bias and response bias show different characteristics. In addition, this option was still likely to be costly, and we would be unable to estimate our costs at the outset.

\section{Developing the online tool}

\section{Choosing the software}

Once we had decided to develop an online questionnaire, the next task was to identify the most suitable software. This was somewhat daunting, given the large choice of software options on the market differing in facilities, contract and licence arrangements, costs, available support and so on (Wright, 2005). There are also variations in the number of researchers allowed access, possibilities for incorporating multimedia and the number of surveys that can be carried out. Additional features of software packages are a facility for 'randomised answer choices' to vary the order of response categories across participants to reduce bias, multiple language options and provision for the visually impaired. Functionality, the availability of support, privacy and cost are among the considerations we took into account in making a choice for the YOR project.

Functionality is a large umbrella covering many different features that may or may not be relevant to any particular survey. As we needed a young person friendly tool for the YOR project, our priority was for a software package that allowed us to present questions clearly, record answers easily and make the survey appealing to young respondents. For example, we wanted to be able to place each question on its own page, use 'branching' to omit any questions not relevant to a particular respondent, have a response mode that was easy to understand and apply, and adopt a 'young' and 'unstuffy' format that enabled pictures or images to be included. We wanted to develop, manage and monitor the survey ourselves, but have access to support on hand if needed. Guaranteeing anonymity to respondents and affordable software were also crucial. Following an excellent demonstration from one recommended provider, we made our choice! 


\section{Content, format, design and style}

Designing the questionnaire presented considerable tensions and challenges in terms of both content and its presentation. To address our research questions, we needed to confront the complexity of religious identity, avoid a Christian-centric focus, promote youthcentredness, and ensure suitability for a range of age and ability levels (see Madge and Hemming, 2011). In terms of presentation, we needed to consider the order of questions to make sure both that key sensitive questions were answered and young people were not disengaged, and to select ways of displaying options and branching questions. Our main priorities were to design questions and response categories that were unambiguous and likely to be easily understood by pupils across most of the secondary school years, and which were suitable for young people whether or not they identified with a particular faith. Moreover, the questionnaire had to be completed within a single-class session - not too long that pupils got bored, but long enough to be able to include necessary questions and generate useful and interesting findings. We also wanted to include some open-ended questions to augment the findings and act as extension activities. In terms of design, some pupils commented that they would like pictures to accompany questions and add interest. It was difficult to post pictures with religious significance that might not influence responses, and instead we inserted colourful abstract designs produced by our research administrator.

The online software included a 'required answer' feature. In general, this was not appropriate in our survey as young people did not have to answer any question they did not want to. However, as we did need them to consent to take part, we used it on the introductory page for this purpose. If young people did not tick this button, they were not permitted to proceed.

\section{Administration of the survey}

\section{Getting the schools on board}


An American paper over 20 years ago recognised how understanding about school organisation is crucial in gaining access for research purposes (Friedman and Orru', 1991). This message has more recently been reinforced by Testa and Coleman (2006) who documented how they accessed just over three thousand 15- to 18-year-old research participants in schools for a UK survey of adolescent sexual health. In their own study, they recruited 18. In their own study, they recruited 18 schools from their purposive sample of 30, losing eight to follow-up, four because of a timetable clash, and two due to 'perceived religious sensitivity of teachers, parents or students'. They refer to their response rate as high, and say it is much better than in many studies.

In the YOR project, a critical first task was getting the schools on board and initiating, as described by Valentine (1999), the 'chain of negotiation' that necessarily occurs. Our initial step was to hold discussions with stakeholders in the research areas to identify the most appropriate community figurehead who supported the research on the one hand and had the respect of schools on the other. We acknowledged the importance, stressed by Testa and Coleman (2006), of establishing a relationship with a key teacher in each school to co-ordinate the exercise, and the next step was to locate a staff member at each school who was keen to collaborate. Schools varied in hierarchical management with some allowing staff much more autonomy to make their own decisions about getting involved than others.

Negotiating access to schools was often a lengthy and sensitive process. Making and maintaining contact involved school visits, telephone calls and emails, many of which did not elicit any response. Furthermore, it was not always easy to identify the best key teacher in a school. For example, the RE teacher in one school whom we had presumed was the most likely person to co-operate with us, did not want to participate but an IT teacher did. In another school / college, the sixth form tutor was especially co-operative, largely reflecting an affinity with universities that came from encouraging pupils to apply for higher education. Table 2 illustrates the 'chain of negotiation' at one school that participated in the survey. 


\begin{tabular}{|c|c|}
\hline Date & Action \\
\hline $4 / 12 / 2009$ & $\begin{array}{l}\text { Letter sent to school with details of the study and letter of support from Local } \\
\text { Authority }\end{array}$ \\
\hline $14 / 12 / 2009$ & $\begin{array}{l}\text { Phone call to school. Head's personal assistant (PA) said would ask Head about } \\
\text { school's involvement and lead contact }\end{array}$ \\
\hline $28 / 01 / 2010$ & $\begin{array}{l}\text { Email sent to Head's PA to remind school about project with copies of original } \\
\text { letters attached. School also asked to confirm receipt of book gift }\end{array}$ \\
\hline $29 / 01 / 2010$ & $\begin{array}{l}\text { School contacted to speak to Head of RE. Spoke to school secretary: contact } \\
\text { unavailable by phone and should be contacted by email. Sent email to Head of } \\
\text { RE to ask about the school's participation. }\end{array}$ \\
\hline $03 / 02 / 2010$ & $\begin{array}{l}\text { Phoned school to speak to Head of RE, but not available. Asked to speak to Head } \\
\text { of ICT and was told to email him and phone back next week }\end{array}$ \\
\hline $03 / 02 / 2010$ & Email sent to Head of ICT to ask if survey could be undertaken in ICT lessons \\
\hline $09 / 02 / 2010$ & $\begin{array}{l}\text { Phoned school and spoke to receptionist who suggested an email to Head of } \\
\text { Citizenship with copy to Head of RE. Email sent to Head of Citizenship and Head } \\
\text { of RE to ask if school would take part in survey. Received email from Head of } \\
\text { Citizenship expressing an interest in taking part. }\end{array}$ \\
\hline $22 / 02 / 2010$ & $\begin{array}{l}\text { Phoned school to speak to Head of Citizenship. Not available but receptionist } \\
\text { said she would email him to ask him to call researcher back. }\end{array}$ \\
\hline $26 / 02 / 2010$ & $\begin{array}{l}\text { Email from Head of RE to say that ICT rooms fully booked and ask if could } \\
\text { conduct survey after Easter. Replied, and received further response confirming } \\
\text { wish to be an active partner in the research. }\end{array}$ \\
\hline $11 / 03 / 2010$ & Sent email to Head of RE to confirm the school was willing to take part. \\
\hline $16 / 03 / 2010$ & $\begin{array}{l}\text { Sent further email to Head of RE to confirm that the survey could be done after } \\
\text { Easter. }\end{array}$ \\
\hline $18 / 03 / 2010$ & Phoned school to speak to the Head of RE. Left message to call back. \\
\hline $22 / 03 / 2010$ & $\begin{array}{l}\text { Phoned school to speak to Head of RE. Receptionist suggested sending email } \\
\text { Sent email sent to Head of RE to arrange participation after Easter. }\end{array}$ \\
\hline $23 / 03 / 2010$ & $\begin{array}{l}\text { Received email from Head of RE to confirm arrangements for after Easter. } \\
\text { Replied to email to ask about time / dates for a meeting. }\end{array}$ \\
\hline $30 / 03 / 2010$ & $\begin{array}{l}\text { Phoned school. Spoke to receptionist as Head of RE unavailable. Said she would } \\
\text { email her to call researcher back. }\end{array}$ \\
\hline $31 / 03 / 2010$ & $\begin{array}{l}\text { Head of RE phoned to confirm survey after Easter. However, unclear about dates } \\
\text { and times. }\end{array}$ \\
\hline
\end{tabular}




\begin{tabular}{|l|l|}
\hline $01 / 04 / 2010$ & Sent Head of RE survey information pack by email. \\
\hline $22 / 04 / 2010$ & School started the survey!! \\
\hline $30 / 04 / 2010$ & 113 (year 8 ), 66 (year 9 ) and 25 (year 10 ) students had completed the survey. \\
\hline
\end{tabular}

Table 2: The 'chain of negotiation' with one participating school

Getting schools on board was a 'give and take' process. Schools were being asked to find enough computers to conduct the online survey with as many as possible pupils from years 8,10 and 12 (as appropriate), but they needed to be sure that taking part was in their interests. They wanted to know that the researchers did not have a hidden agenda, particularly when the sensitive subject of religion was under investigation, and that participation performed an educational role. Our case was built on enabling schools to address Ofsted targets relating to listening to young people and social cohesion. We also promised speedy and school-specific feedback from the survey to act as a stimulus for discussion and raise the profile of the topic of religion. As a thank you to schools that showed an interest in our research, we donated a book on religion for their library whether or not they decided to take part. Overall, we fulfilled the main recommendations of Sturgis and others (2006) for raising response rates in school surveys.

\section{The pilot phase}

Two pilot phases tested the content of the questionnaire, its online administration and time to completion. The first was most intensive and led to extensive changes, whereas the second resulted in minimal modifications. In the first phase, 86 pupils from two schools completed the questionnaire online and 24 from the same schools completed it in paper format. In the second phase, 47 pupils completed the questionnaire online and another class completed it as a group using an interactive white board. A small group of 33 pupils were also asked six questions on the online format of the questionnaire. All had completed an online questionnaire before, and all thought a computer-based survey was 'easier' and 'more fun' than one that was paper-based. Well over half liked the pictures we had included to make it more colourful. Interestingly, although $79 \%$ thought they would have answered the questions similarly whatever the format of the questionnaire, $21 \%$ thought they might 
have answered differently had they been given a paper questionnaire. Unfortunately, these responses were provided anonymously and we did not have any further details on quite what they meant. Further exploration of this issue would be valuable.

The main changes following the phase 1 pilot were to: shorten the questionnaire; simplify some of the language (e.g. pupils understood 'affected' better than 'influenced' in sentences such as 'How much are the following parts of your everyday life affected/ influenced by your religious beliefs?'); remove questions that involved ranking answers (many pupils did not understand either the task or the manual operation involved); use a maximum of five scale points when employing Likert scales; reduce the amount of text for respondents to read (pupils skipped over instructions if these were overly long); shorten questions (and in some cases split them into two sections); and restrict the use of openended questions (pupils rarely responded to these). The pilot also identified questions pupils did not understand or know why they were being asked. As a result, a list of 'frequently asked questions' was developed for teachers to answer pupil queries. Another main change was the introduction of a progress bar to let pupils see how far they had got through the questionnaire, and some motivational comments such as 'you're almost there!' to encourage them to continue (and make it more like a paper questionnaire where you can see what, and how many, questions are to come).

All pilots were carried out with year 9 pupils in target schools to avoid the possibility that individual young people would be involved in both pilot and main survey phases.

\section{Preparing schools for undertaking the survey}

Once schools agreed to take part, they were sent information packs by post and email to facilitate the process. These included guidance for teachers/tutors on preparing for the survey (e.g. providing parents of pupils under 16 years with the opportunity to opt their child out of the survey if they so wished, and telling pupils about the survey so they could give their informed consent) and carrying it out. This guidance included the unique daily password for the questionnaire (see below), contact information for questions and queries, and a series of frequently asked questions that pupils had posed during the pilot phases. In 
addition, the information packs included parental consent letters, information leaflets on the study, a record sheet to record numbers of pupils not taking part in the survey, posters for schools wishing to publicise the project and a voucher to cover printing costs.

Schools were asked whether they wished to conduct the survey themselves or whether they would like a member of the research team (or a volunteer especially trained for the role), to come in to provide support. In the vast majority of cases, schools preferred to conduct the survey on their own as this allowed them more flexibility.

\section{Maximising the validity of the study}

A limitation of any survey is that findings have to be accepted as reported. We know, however, that not all responses will be fully accurate. There are at least five reasons why error may creep in. Respondents may:

- not understand questions and respond 'incorrectly';

- not wish to answer questions and respond 'incorrectly';

- not take the survey seriously and provide random answers;

- deliberately overreport desirable behaviours and underreport undesirable ones ('impression management': Booth-Kewley and others, 2007);

- give honestly believed but overly positive reports about themselves ('self-deceptive enhancement': Booth-Kewley and others, 2007).

We took whatever measures we could to minimise bias in these ways. The lengthy development of the questionnaire, including the pilot stage, led to as much simplification of questions as we could manage, and our messages to respondents at all stages of the survey emphasised how they need answer only the questions they wished to. It is hoped that these measures reduced the frequency of incorrect or random responses. Nonetheless, and despite our efforts, it seemed from what pupils said that we were not able to avoid all misleading responses. Some pupils said there had been questions they could not 
understand and a few, whether with honesty or bravado, confessed to clicking random responses.

We have less evidence that pupils / students demonstrated either impression management or self-deceptive enhancement. The questionnaire did not ask about conventionally desirable or undesirable behaviours, although young people might have felt there was an onus on them to respond one way or another, perhaps on their religious beliefs or friends or families. Again we tried to minimise these effects by stressing that we were interested in everyone's views, whether or not they had a religion, that there were no right or wrong answers, and that all responses were completely anonymous. We cannot assess any remaining impact of this kind, although one young person did volunteer how 'The questions were not too personal'.

\section{Security of the questionnaire}

A strength of the online questionnaire, which is at once its weakness, is that it can be completed almost anywhere at any time. On the negative side, this can reduce control over respondents and hence the study sample. Some online surveys are open to anyone who can access them and do not place restrictions on who may complete the questionnaire or how many times they may complete it.

The YOR project was particularly concerned to impose some regulation over the resultant sample, and considered the options carefully. We needed an easily manageable solution and immediately rejected the possibility of sending questionnaires to potential participants' email addresses. This option has the advantage of allowing recipients to respond only once (they are unsubscribed once they have completed the questionnaire), but was not easy in our case as we did not know who would be taking part. It would have been an onerous task for teachers to provide us with this information in advance, and would reduce confidentiality in what was billed as an anonymous study.

The main alternative was to post the questionnaire on our website and provide joining instructions. This approach, nonetheless, gave rise to further concerns. If we gave an easy 
password to access the survey, young people might remember it and tell and/or show friends and parents. (The password 'Religion' had been guessed in the pilot!) This could mean parental pressure on young people before they had taken part, those outside our sample completing the questionnaire, and/or young people completing it more than once. If, on the other hand, we used a complicated password, young people might get it wrong and cause delays to the start of the survey. In addition, we wanted to make the questionnaire available for teachers and fellow researchers. If we had just a single questionnaire with a single password, we ran the risk that teachers or researchers would unavoidably and artificially inflate and distort the sample.

Our solution was somewhat complex but nonetheless met our requirements. First, we produced parallel versions of the questionnaire for pupils / students and teachers / researchers to access, second we changed the password on the pupil version on a daily basis (using common everyday words and providing teachers with the necessary information), and third we turned the survey facility on every morning and off at the end of the school day.

\section{Response to the survey}

The YOR survey ran live for six weeks prior to the Easter break, and was opened again after the holidays for a further two weeks. It achieved over 10500 responses, most of which were complete, and was successful in meeting its target. The final number of participating schools and response rates within the targeted age groups are shown in Table 3.

\begin{tabular}{|l|l|l|l|}
\hline & $\begin{array}{l}\text { Research } \\
\text { area A }\end{array}$ & $\begin{array}{l}\text { Research } \\
\text { area B }\end{array}$ & $\begin{array}{l}\text { Research } \\
\text { area C }\end{array}$ \\
\hline Proportion of participating secondary schools and colleges & $10 / 25$ & $18 / 21$ & $11 / 17$ \\
\hline Total number of responses & 2855 & 4160 & 3361 \\
\hline $\begin{array}{l}\text { Responses as an approximate proportion of eligible pupils / } \\
\text { students (\%) }\end{array}$ & 17 & 50 & 35 \\
\hline
\end{tabular}

Table 3: Participating secondary schools/colleges and pupils 
Generally speaking, our strategy for engaging schools, the length of the survey period and the use of an online survey appeared validated. First, almost all schools that agreed to take part in the survey did so. Reasons for schools not taking part, where these could be ascertained, included concerns that participation would create too much work for staff, exam revision time might be disrupted, or the school might be misrepresented in any published findings (despite our assurances to the contrary). In a very small number of cases, schools were not interested in taking part or had particular issues that made participation difficult, and in isolated instances we did not manage to make contact with the relevant representative to explore the possibility of participation. Second, six weeks (with two weeks' grace for a few schools) allowed us to achieve our projected sample size. Figure 2 shows how responses over the survey period were spread fairly evenly over time, but with some reduction in activity immediately before and after school holidays. And third, few difficulties were encountered through the use of an online questionnaire accessed through the researchers' university website. Nonetheless, practical difficulties in booking ICT suites, schools not always having enough computers to enable whole classes to complete the survey, occasional internet crashes, an instance when a fuse blew on a laptop trolley and another when a school had omitted to turn off a filter are all likely to have had some impact on the overall sample size.

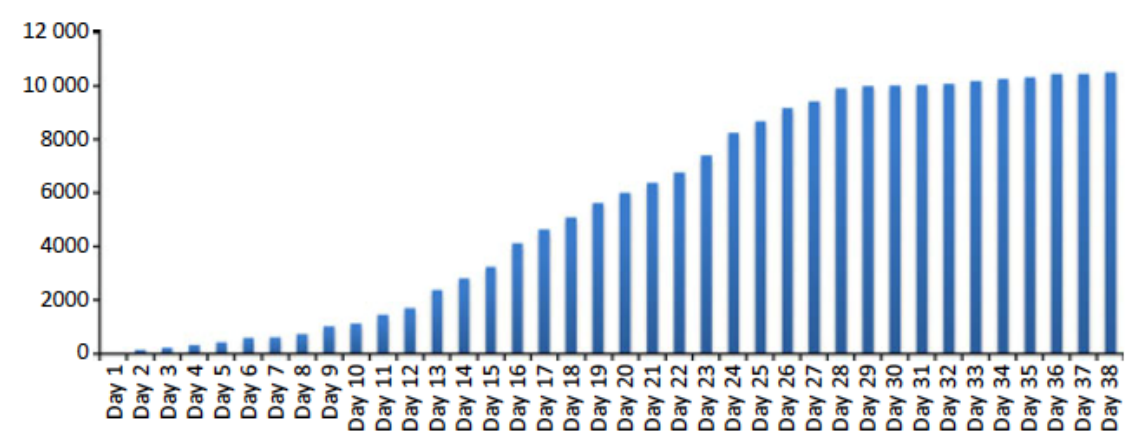

Figure 2: Cumulative responses over the survey period. 


\section{Conclusions}

The main lessons learned from the YOR project survey related, first, to the politics of gaining access to schools and, second, to the development and administration of an online survey. Getting schools to take part in the survey tended to be a lengthy process of establishing the best staff contacts and negotiating participation. Schools are busy institutions and persistence without pressure was, we felt, key to our success. Nonetheless, it was essential to demonstrate that our survey had an educational component and stress ways in which teachers and students would benefit from participation (see Sturgis and others, 2006). We also promised feedback on initial findings from the outset, and delivered on this promise within a month of final data collection: quick feedback played an important part in keeping some schools engaged with later, post-survey stages of the research. An unconditional incentive to schools, in the form of a dictionary of religions, was additionally provided.

Schools provided a high level of co-operation, and many teachers were positive:

Generally the feedback [from the survey] was very positive. The majority of pupils enjoyed engaging with the questions and I think some were stimulated by the fact that they had never considered these kind of questions before.

Briefly I would like to express how good and informative the project has been. The students without exception enjoyed answering the questions and I now feel I have a better understanding of our student demographic and faith perspectives.

The decision to use an online questionnaire for the YOR survey was vindicated. Schools, almost without exception, provided the level of co-operation they had pledged. Computers were found, sessions organised and questionnaires completed. Apart from a few extra days at the end of the survey, the planned timeframe was maintained. The questionnaire itself seemed to work too. Most respondents answered most questions and answered them appropriately. Many also included long and thoughtful answers to the two open-ended 'essay' questions. 
We sought young people's views, either formally or informally, at all stages of the survey. Unsurprisingly, these were mixed. Reflecting on the questionnaire, some seemed fairly indifferent:

I thought it was quite boring. (male)

I weren't really bothered about it. (female)

Others, however, reported a positive impact:

I thought it was fine. I learned a bit about myself.

Very nice. It made you think about stuff. How your life is and that. (male)

I reckon it was a very good idea to do it and when we write it down we think about our religious views. So I reckon it was a good questionnaire. (female)

We conclude that successful research in schools has to be planned carefully in collaboration with key members of staff, and justified as an educational activity. Schools and pupils put in time and energy to make it work, and this input needs to be recognised and reciprocated. Finally, the conduct of the YOR survey enabled the researchers to gain a good picture of young people's experiences of religion in the study areas to provide a good basis for subsequent qualitative investigation.

\section{Acknowledgement}

The research outlined in this paper is funded by the AHRC/ESRC Religion in Society programme, Grant Number AH/ G014086/1 


\section{References}

Booth-Kewley S, Larson GE, Miyoshi DK. 2007. Social desirability effects on computerized and paperand-pencil questionnaires. Computers in Human Behavior 23: 463-477.

David M, Edwards R, Alldred P. 2001. Children and school-based research: 'informed consent' or 'educated consent'? British Educational Research Journal 27: 347-365.

Dillman DA. 2000. Mail and Internet Surveys: The Tailored Design Method, 2nd edn. John Wiley \& Sons: New York.

Dinella LM, Ladd G. 2009. Building and maintaining relationships with stakeholders. In Conducting Science-Based Psychology Research in Schools. Dinella LM (ed.). American Psychological Association: Washington; 9-31.

Feigelson ME, Dwight SA. 2000. Can asking questions by computer improve the candidness of responding? A meta-analytic perspective. Consulting Psychology Journal: Practice and Research 52: 248-255.

Friedman J, Orru` M. 1991. Organizational access to research settings: entering secondary schools. The American Sociologist 22: 117-136.

Gill J. 2003. Who Guards the Guardians Now? Ethical Dilemmas in Conducting School-based Research. University of South Australia: Auckland.

Joinson AN. 2001. Self-disclosure in computer-mediated communication: the role of selfawareness and visual anonymity. European Journal of Social Psychology 31: 177-192.

LaBrie J, Earleywine M, Lamb T, Shelesky K. 2006. Comparing electronic-keypad responses to paperand-pencil questionnaires in group assessments of alcohol consumption and related attitudes. Addictive Behaviors 31: 2334-2338. 
Madge N, Hemming PJ. 2011 (chapter submitted, book in preparation). Using a survey to investigate the role of religion in young people's lives. In Innovative Methods in the Study of Religion: Research in Practice. Woodhead L (ed.). Oxford University Press: Oxford.

Martin G. 1995. OPTIONS: Target, Systems Update. Addiction Research Foundation: Toronto.

Postmes T, Spears R, Sakhel K, de Groot D. 2001. Social influence in computer-mediated communication: the effects of anonymity on group behavior. Personality \& Social Psychology Bulletin 27: 1243-1254.

Query J, Wright KB. 2003. Assessing communication competence in an on-line study: toward informing subsequent interventions among older adults with cancer, their lay caregivers, and peers. Health Communication 15: 205-219.

Ritter P, Lorig K, Laurent D, Matthews K. 2004. Internet versus mailed questionnaires: a randomized comparison. Journal of Medical Internet Research 6: e29.

Sax LJ, Gilmartin SK, Bryant AN. 2003. Assessing response rates and nonresponse bias in web and paper surveys. Research in Higher Education 44: 409-432.

Sturgis P, Smith P, Hughes G. 2006. A Study of Suitable Methods for Raising Response Rates in School Surveys. Research Report No. 721. Department for Education and Skills: London.

Suler J. 2004. The online disinhibition effect. CyberPsychology \& Behavior 7: 321-326. Testa AC, Coleman LM. 2006. Accessing research participants in schools: a case study of a UK adolescent sexual health survey. Health Education Research 21: 518-526.

Valentine G. 1999. Being seen and heard? The ethical complexities of working with children and young people at home and at school. Ethics, Place and Environment 2: 141-155. 
Vallejo MA, Jorda'n CM, Diaz MI, Comeche MI, Ortega J. 2007. Psychological assessment via the internet: a reliability and validity study of online (vs paper-and-pencil) versions of the General Health Questionnaire-28 (GHQ-28) and the Symptoms Check-List-90-Revised (SCL90-R). Journal of Medical Internet Research 9: e2.

Wright KB. 2005. Researching internet-based populations: advantages and disadvantages of online survey research, online questionnaire authoring software packages, and web survey services. Journal of Computer-Mediated Communication 10: Article 11. Available at http://jcmc.indiana.edu/vol10/issue3/wright.html [Accessed on 10 March 2011].

Younie S. 2006. Implementing government policy on ICT in education: lessons learnt. Education and Information Technologies 11: 385-400. 